\title{
Kwetsbaarheid tijdens de zwangerschap is meer dan een disbalans tussen risicofactoren en beschermende factoren
}

\author{
Esther I. Feijen-de Jong - J. Catja Warmelink · Maria Dalmaijer · Relinde A. van der Stouwe
}

Geaccepteerd op: 1 juni 2021 / Published online: 8 juli 2021

(C) The Author(s) 2021

\begin{abstract}
Samenvatting Het concept kwetsbaarheid tijdens de zwangerschap is een complex en veelzijdig begrip. Om meer inzicht te krijgen in de complexiteit van kwetsbaarheid gebruiken de onderzoekers van de vakgroep Verloskundige wetenschap in Groningen in hun onderzoek naar interventies voor kwetsbare zwangeren het model van Briscoe et al. In dit model interacteren bedreigingen, herstelmogelijkheden en barrières met elkaar. Willen de interventies die ontwikkeld zijn voor kwetsbare zwangeren optimaal gebruikt worden, dan is meer aandacht nodig voor barrières die de toegang tot de juiste zorg of hulp in de weg staan.
\end{abstract}

Trefwoorden model - kwetsbaarheid · zwangerschap · Noord-Nederland · barrières · gezondheidszorg

Vulnerability during pregnancy is more than an imbalance between risk factors and protective factors

Abstract The concept of vulnerability during pregnancy is complex and multifaceted. To unpack this complexity researchers of the department of Midwifery Science North Netherlands have utilized a framework put forward by Briscoe et al. in their

\footnotetext{
Dr. E. I. Feijen-de Jong $(\bowtie) \cdot$ Dr. J. C. Warmelink .

M. Dalmaijer · R. A. van der Stouwe

Universitair Medisch Centrum Groningen, Afdeling

Huisartsgeneeskunde, Rijksuniversiteit Groningen,

Groningen, Nederland

Vakgroep Verloskundige wetenschap, Rijksuniversiteit Groningen, Groningen, Nederland

Academie Verloskunde Amsterdam Groningen, Groningen, Nederland

e.i.feijen-de.jong@umcg.nl
}

study about interventions for vulnerable pregnant women. This framework models how threats, recovery options and barriers interact with each other. For an optimal use of the developed interventions for vulnerable pregnant women, professionals need to pay more attention to barriers that impede access to proper care or help.

Keywords Framework - Vulnerability · Pregnancy · North Netherlands · Barriers · Health care

\section{Aanleiding}

Zwangere vrouwen in een kwetsbare situatie hebben een verhoogd risico op ongunstige zwangerschapsuitkomsten, zoals perinatale sterfte [1-4]. Omdat betrokken zorgverleners onvoldoende inzicht hebben in de omstandigheden van zwangere vrouwen of deze verschillend beoordelen, krijgen kwetsbare zwangeren niet altijd tijdig de juiste hulp [2]. In Rotterdam werken onderzoekers, medische en sociale zorgverleners samen aan een eenduidige definitie, met als doel deze vrouwen en hun gezin de juiste zorg op de juiste plek te bieden [2]. Kwetsbaarheid definiëren ze als een disbalans tussen risicofactoren en beschermende factoren. Er zijn allerlei risicofactoren die zwangere vrouwen kwetsbaar kunnen maken, zoals een tienerzwangerschap, roken, het hebben van een chronische ziekte of wonen in een achterstandswijk [1, 3-5]. Tegelijkertijd zijn er ook factoren of omstandigheden die vrouwen beschermen tegen kwetsbaar worden of waardoor de kwetsbaarheid afneemt [2, 4]. Voorbeelden daarvan zijn het hebben van een sociaal netwerk, zelfredzaam zijn of beschikken over goede gezondheidsvaardigheden.

Naast de risico- en beschermende factoren stellen wij dat er nog een ander aspect van invloed is op de kwetsbaarheid tijdens de zwangerschap, namelijk de 
barrières die de toegang tot de juiste zorg of hulp belemmeren. Willen de interventies die ontwikkeld zijn voor kwetsbare zwangeren optimaal gebruikt worden, dan zullen zorgverleners en beleidsmakers zich bewust moeten worden van mogelijke barrières in de zorgverlening.

\section{Definitie van kwetsbare zwangeren}

Het Nederlandse geboortezorgsysteem is gebaseerd op een risicoselectiesysteem waarbij eerstelijnsverloskundigen of huisartsen verantwoordelijk zijn voor de zorg voor laagrisicovrouwen. Hoogrisicovrouwen worden begeleid door tweedelijns- of derdelijnsverloskundigen en gynaecologen [1]. Sinds 1999 hanteren verloskundige zorgverleners bij deze risicoselectie de Verloskundige Indicatielijst, waarin voornamelijk lichamelijke en enkele psychische ziektebeelden als risicofactoren worden benoemd [1]. In het laatste decennium is er toenemende aandacht voor sociale risicofactoren en sociale verloskunde [1,5]. Ook sociale omstandigheden kunnen een effect hebben op perinatale morbiditeit en mortaliteit. Dit kan te maken hebben met een ongezonde leefstijl of stressvolle woonomstandigheden, beperkte gezondheidsvaardigheden en de toegang tot de zorg [5].

Met de toenemende aandacht voor sociale verloskunde heeft ook het begrip 'kwetsbare zwangeren' in de geboortezorg haar intrede gedaan. Deze term wordt vaak gebruikt om zwangeren aan te duiden met een of meer psychische en/of sociale risicofactoren $[1,2,4,5]$.

Het Regionaal Consortium Zwangerschap \& Geboorte Zuidwest Nederland definieerde in 2016 kwetsbaarheid in de zwangerschap als volgt: 'het aanwezig zijn van psychopathologische, psychosociale problemen en/of middelengebruik en het tegelijkertijd hebben van een tekort aan persoonlijke middelen om het negatieve effect hiervan op de zwangerschap en bevalling te verminderen, uit eigen kracht of door effectief gebruik te maken van de zorg' [6]. In deze definitie is kwetsbaarheid de netto-uitkomst van risicofactoren en de beschikbaarheid van persoonlijke en sociale bronnen [4]. Dat suggereert dat kwetsbaarheid een optel- of aftreksom is: beschermende factoren kunnen de mate van kwetsbaarheid laten afnemen of tot nul reduceren.

In vervolgonderzoek door het Erasmus MC en de gemeente Rotterdam nuanceren Van der Meer et al. deze definitie. Ze stellen dat kwetsbaarheid een disbalans is tussen risicofactoren en beschermende factoren [2]. Van der Meer et al. hebben een stroomdiagram ontwikkeld waarin onderscheid wordt gemaakt tussen zelfredzame zwangere vrouwen, potentieel kwetsbare zwangere vrouwen, kwetsbare zwangere vrouwen en zeer kwetsbare zwangere vrouwen [2]. De inschatting van de mate van kwetsbaarheid gebeurt in samenspraak tussen hulp- en zorgverleners en de vrouw in kwestie. Het vaststellen van kwetsbaarheid in de zwangerschap is dus geen optel- of aftreksom, maar komt in een dialoog tot stand.

\section{Onderzoek naar interventies voor kwetsbare zwangeren in Noord-Nederland}

De vakgroep Verloskundige wetenschap is in 2019 in samenwerking met het consortium Zwangerschap en Geboorte Noord-Nederland gestart met het door ZonMw gesubsidieerde project 'Samen kwetsbaar, samen sterk' (officiële titel: Identifying and improving tailored care interventions for vulnerable pregnant women). In dit project wordt onderzocht op welke manier de zorg voor kwetsbare zwangeren in Noord-Nederland beter kan aansluiten bij de behoeften en wensen van deze vrouwen. Het relatief hoge percentage bewoners met een lage sociaaleconomische status (SES) in Noord-Nederland en de slechtere zwangerschapsuitkomsten vormen de aanleiding voor dit onderzoek. Een lage SES is een van de risicofactoren die tot kwetsbaarheid tijdens de zwangerschap kan leiden $[1-3,5]$. We gaan er dan ook vanuit dat in Noord-Nederland een relatief hoog percentage zwangeren kwetsbaar is. Voor deze zwangeren zijn diverse interventies ontwikkeld, waarvan er veel niet volledig geïmplementeerd zijn en de indruk bestaat dat ze niet optimaal gebruikt worden [7].

Het project 'Samen kwetsbaar, samen sterk' bestaat uit twee fasen. In de eerste fase hebben we bestaande interventies voor kwetsbare zwangeren in de negen Verloskundige Samenwerkingsverbanden (VSV's) in Noord-Nederland geïnventariseerd en de implementatiegraad ervan onderzocht [7]. Daarnaast hebben interviews plaatsgevonden met meer dan zestig zorgverleners van verschillende disciplines in het medische en sociale domein over de factoren die het gebruik van interventies beïnvloeden, en met zeventien zwangere vrouwen of moeders die tijdens hun zwangerschap van een interventie gebruik hebben gemaakt $[8,9]$. In de tweede fase van het onderzoek, die nog van start moet gaan, gaan twee learning communities van zorgverleners en zwangeren/moeders onderzoeken hoe het gebruik van de interventies voor kwetsbare zwangeren geoptimaliseerd kan worden.

Aanvankelijk herkenden we in onze data veel van het denken over kwetsbaarheid tijdens de zwangerschap zoals beschreven door van der Meer et al. [2]. Tegelijkertijd wezen zorgverleners op de complexiteit van de kwetsbare situaties waarin zwangere vrouwen kunnen leven. Ook vrouwen bij wie wel beschermende factoren aanwezig zijn kunnen kwetsbaar worden omdat ze geen toegang krijgen tot de (extra) zorg die hen zou kunnen ondersteunen. Om die complexiteit beter te begrijpen zijn we onze data opnieuw gaan analyseren op basis van het model van Briscoe et al. [10]. In dat model interacteren drie aspecten met elkaar: bedreigingen, herstelmogelijkheden en barrières (zie fig. 1). 


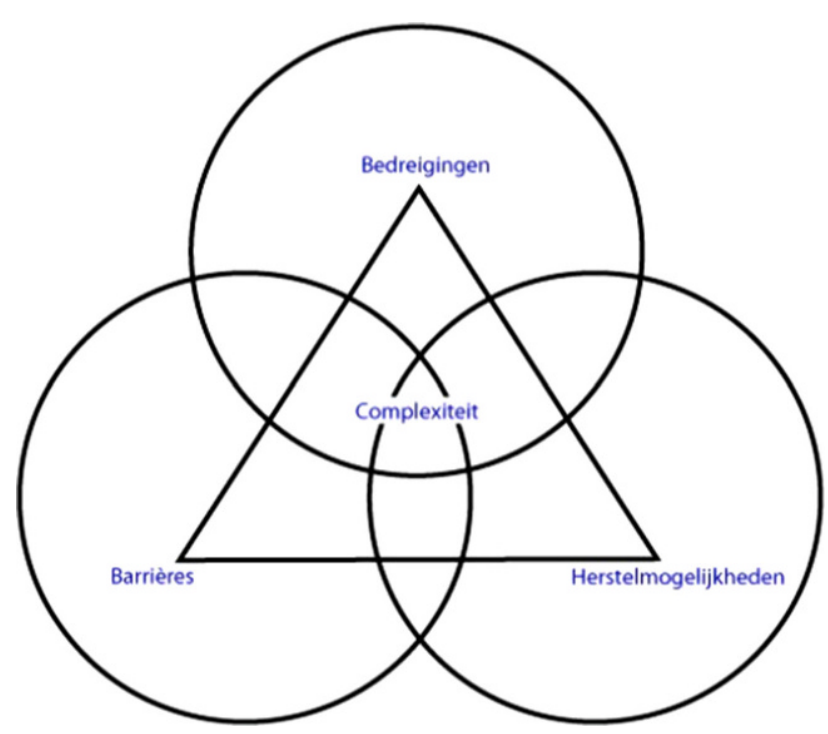

Figuur 1 Vereenvoudigd model van Briscoe et al. [10]

Bedreigingen kunnen van biologische, psychische of sociologische aard zijn [10]. Biologische bedreigingen kunnen bijvoorbeeld te maken hebben de lichamelijke conditie, zoals een chronische ziekte of een meerlingzwangerschap. Psychische bedreiging kan een depressie (in de voorgeschiedenis) zijn. Een voorbeeld van een bedreiging van sociologische aard is een ongezonde leefstijl in de leefomgeving van de vrouw. Of deze bedreigingen tot kwetsbaarheid leiden, hangt enerzijds af van de mogelijkheden die aanwezig zijn om vrouwen te ondersteunen en anderzijds van barrières die de toegang tot de zorg kunnen belemmeren. Als voorbeelden van herstelmogelijkheden noemen Briscoe et al.: toegenomen zelfvertrouwen, sociale steun, zorg op maat, warme vertrouwensrelaties. Barrières of obstakels worden gecreëerd door beperkte toegang tot zorg, doordat de zwangere zich terugtrekt van de mensen en zorgverleners om haar heen en door de onpersoonlijke benadering van zorgverleners [10].

\section{Barrières in de toegang tot de zorg}

In de onderzoekgegevens die we in de eerste fase van ons project hebben we verzameld vonden we een veelheid aan mogelijke bedreigingen van lichamelijke, psychische of sociologische aard. Ook de door Briscoe et al. genoemde herstelmogelijkheden en barrières herkennen we in onze data. In dit artikel richten we onze focus op de barrières die zich kunnen voordoen binnen het domein van de organisatie van de zorg, van de zorgverlener, van de vrouw zelf en van haar sociale kring. Elk van deze vier domeinen zullen we toelichten.

\section{De organisatie van de zorg}

Verschillende interventies en hulpverlenende instanties kunnen zwangeren in kwetsbare situaties ondersteunen. Een overzicht hiervan ontbreekt vaak bij de betrokken zorgverleners. Bij de zorg voor kwetsbare zwangeren zijn veelal medische en sociale zorgverleners van verschillende disciplines betrokken. Coördinatie van de zorg ontbreekt, waardoor vrouwen de weg kwijtraken in de organisatie, afhaken en geen gebruikmaken van de ondersteuningsmogelijkheden.

\section{De zorgverlener}

We beschouwen een negatieve attitude van de zorgverlener jegens de doelgroep als een barrière. In de interviews uiten sommige zorgverleners een vooringenomenheid over de zin van het inzetten van interventies bij kwetsbare zwangeren. Een andere barrière bij de zorgverlener betreft de angst om te stigmatiseren. Soms durven zorgverleners uit angst daarvoor bepaalde problemen niet bespreekbaar te maken, waardoor vrouwen zelfs geen hulp aangeboden krijgen. Andere zorgverleners noemden de angst voor het schaden van de relatie met hun cliënt. Ze vinden dat ze bijvoorbeeld het ongezonde gedrag of de onveilige thuissituatie moeten bespreken en zijn op voorhand bang voor de terugtrekreactie van de cliënt.

\section{De kwetsbare zwangere}

In het domein van de zwangere vormt de angst voor stigmatisering ook een barrière om gebruik te maken van extra zorg. Vrouwen geven aan bang te zijn om een etiket opgeplakt te krijgen. Bijvoorbeeld het etiket dat de vrouw niet zelf voor haar kind kan zorgen als ze extra ondersteuning krijgt van een Stevig Ouderschap-verpleegkundige.

\section{De sociale kring}

In het domein van de sociale kring van de zwangere kan de sociale norm een barrière vormen. Als roken de norm in het netwerk is, kan het voor een zwangere lastig zijn om te stoppen met roken of ondersteuning te accepteren bij het stoppen. Dit laatste is tevens een voorbeeld van de interactie tussen bedreigingen, herstelmogelijkheden en barrières die het begrip kwetsbaarheid complex maakt. Het ontbreken van een netwerk wordt door veel van de geïnterviewden als een bedreiging van sociale aard gezien. Is er wel sprake van een netwerk, dan kan het verschil maken of een tienermoeder kwetsbaar of veerkrachtig is. Tegelijkertijd kan de sociale norm binnen een netwerk een barrière vormen voor het accepteren van hulp. 


\section{Niveaus van zorg}

Naast de barrières op de vier verschillende domeinen kunnen ze ook beschouwd worden vanuit micro-, meso- en macroniveau. Op microniveau kan een wantrouwende houding van de vrouw ervoor zorgen dat ze geen extra zorg accepteert. Aan dit wantrouwen kunnen eerdere negatieve ervaringen met hulpverlening ten grondslag liggen, die te maken kunnen hebben met gebrekkige coördinatie van de zorg (mesoniveau) en het niet kunnen voldoen aan bepaalde criteria, waardoor de zorg niet vergoed wordt (macroniveau).

\section{De beperktheid van een definitie}

Kwetsbaarheid tijdens de zwangerschap is dus meer dan een disbalans tussen risico- en beschermende factoren. Wij definiëren, naar analogie van Briscoe, kwetsbaarheid in de zwangerschap als een proces waarbij bedreigingen van lichamelijke, psychische of sociologische aard, interacteren met herstelmogelijkheden en barrières die de toegang tot de zorg of hulpverlening belemmeren. Net als Briscoe et al. zien wij kwetsbaarheid als een persoonlijk en complex proces - het is geen status quo [10]. Dat maakt het zeer lastig en wellicht onmogelijk om het begrip kwetsbare zwangere te operationaliseren.

Tegelijkertijd onderschrijven we het doel van een eenduidige definitie: waarborgen dat zwangere vrouwen met risicofactoren van welke aard dan ook, tijdig de juiste hulp of ondersteuning ontvangen [2]. Juist daarom pleiten we ervoor dat er naast het bespreken van risico- en beschermende factoren ook aandacht besteed wordt aan de barrières die de toegang tot de juiste zorg of hulp belemmeren. Die barrières bevinden zich op het individuele niveau van de zorgverlener of de vrouw, op het niveau van de sociale leefomgeving, en ook op meso- en macroniveau van onze samenleving en de organisatie van zorg. Deze verschillende niveaus dragen bij aan de complexe interactie tussen de bedreigingen, herstelmogelijkheden en barrières.

Ook de onderzoekers in Rotterdam onderkennen individuele en contextuele niveaus van factoren die tot kwetsbaarheid in de zwangerschap kunnen leiden $[2,4]$. Het gebruik van de zorg is bijvoorbeeld in hun definitie een beschermende factor als het aanwezig is en een risicofactor als het afwezig is. In de uitwerking van hun definitie in de vorm van het stroomdiagram waarmee zorgverleners kwetsbare vrouwen kunnen identificeren en doorgeleiden naar adequate hulp [2], lijken de barrières die vrouwen de toegang tot die adequate hulp belemmeren echter geen rol te spelen. In onze definitie lichten wij de barrières er als een apart aspect uit, waarbij we verschillende niveaus onderscheiden. Dat is nodig om de barrières op micro-, meso- en macroniveau op de juiste manier te kunnen aanpakken.
We hopen dat we een bijdrage leveren aan de bewustwording van de barrières in de zorg voor kwetsbare zwangeren. In het tweede deel van ons project 'Samen kwetsbaar, samen sterk' werken we aan manieren waarop deze barrières geslecht kunnen worden.

Open Access This article is licensed under a Creative Commons Attribution 4.0 International License, which permits use, sharing, adaptation, distribution and reproduction in any medium or format, as long as you give appropriate credit to the original author(s) and the source, provide a link to the Creative Commons licence, and indicate if changes were made. The images or other third party material in this article are included in the article's Creative Commons licence, unless indicated otherwise in a credit line to the material. If material is not included in the article's Creative Commons licence and your intended use is not permitted by statutory regulation or exceeds the permitted use, you will need to obtain permission directly from the copyright holder. To view a copy of this licence, visit http://creativecommons.org/licenses/by/4.0/.

\section{Literatuur}

1. Wildschut HIJ, WaelputAJM, Paarlberg KM, et al. De kwetsbare (aanstaande) moeder. In: Wildschut H, Boesveld I, redactie. Integrale geboortezorg. Houten: Bohn Stafleu van Loghum; 2018.

2. Meer L van der, Ernst HB, Blanchette L, et al. Een kwetsbare zwangere, wat is dat eigenlijk? Med Contact. 2020;75(22):34-6.

3. Koninklijke Nederlandse Organisatie van Verloskundigen. Handreiking Kwetsbare Zwangeren. 2017. https://www. knov.nl/serve/file/knov.nl/knov_downloads/2714/file/ 20170622_KNOV_Handreiking_kwetsbare_zwangeren_ versie_FINAL.pdf. Geraadpleegd op: 24 nov 2020.

4. Groot N de, Venekamp AA, Torij HW, et al. Vulnerable pregnant women in antenatal practice: caregiver's perception of workload, associated burden and agreement with objective caseload, and the influence of a structured organisation of antenatal riskmanagement. Midwifery. 2016;40:153-61.

5. Steegers EA. Sociale verloskunde: gelijke kansen op een gezonde start. Ned Tijdschr Geneeskd. 2017;161:D2277.

6. Groot N de, Venekamp AA, Torij HW, et al. Project Samen Werken aan Zorg voor Kwetsbare Zwangeren. Regionaal Consortium Zwangerschap Geboorte Zuidwest Nederland. Internetsite Kennispoort Verloskunde. 2019. https://www.kennispoort-verloskunde. $\mathrm{nl} / \mathrm{wp}$-content/uploads/kennispoort2014/Parallelsessie \%204\%20-\%20Nynke\%20de\%20Groot.pdf. Geraadpleegd op: 24 nov 2020.

7. Warmelink JC, Stouwe RA van der, Dalmaijer M, et al. Onderzoeksverslag. Overzicht van de implementatiegraad van interventies voor zwangeren in een kwetsbare situatie in Noord-Nederland. Midwifery Science Noord-Nederland. 2021. https://zwangerschapengeboorte-nn.nl/ wp/wp-content/uploads/2021/03/Implementatiegraadinterventies-kwetsbare-zwangeren-Noord-Nederlandspread.pdf. Geraadpleegd op: 29 apr 2021.

8. Feijen-de Jong EI, Warmelink JC, Stouwe RA van der, et al. Interventions for vulnerable pregnant women: factors influencing culturally-appropriate implementation according to health professionals. 2021. Submitted.

9. Feijen-de Jong EI, Dalmaijer M, Jansen DECM, et al. Experiences and needs of vulnerable women with regard to 


\section{Forum}

receiving additional interventions in maternity care; a qualitative study. 2021. Submitted.

10. Briscoe L, Lavender T, McGowan L. A concept analysis of women's vulnerability during pregnancy, birth and the postnatal period. JAdv Nurs. 2016;72:2330-45. 